\title{
Ações Educativas e Formação Cidadã: Iniciativas e Resultados de um Programa de Educação Ambiental com Comunidades de Pescadores Artesanais Marítimos do Litoral Centro-Norte do Estado do Espírito Santo, Brasil ${ }^{1}$ \\ Educational Actions and Citizenship Education: Activities and Results of an Environmental Education Program on Artisanal Marine Fishery Communities in Centre-North Coast of Espírito Santo State, Brazil
}

George Bassul Areias ${ }^{\mathrm{a}}$; Vinicius Francisco Marchese*b; Suelem Simão Alves Celantec; Augusto Cesar Salomão Mozine ${ }^{\mathrm{c}}$ \author{
Matemática. ES, Brasil. \\ 'Universidade Federal do Espírito Santo. ES, Brasil. \\ 'Universidade Vila Velha. ES, Brasil. \\ *E-mail: vinicius.marchese@uvv.br
}

anstituto Federal de Educação, Ciência e Tecnologia do Espírito Santo, Programa de Pós-Graduação Stricto Sensu em Educação em Ciências e

\begin{abstract}
Resumo
Este artigo visa analisar os resultados da integração do modo de vida de Comunidades de Pescadores Artesanais Marítimos a novos ambientes e conhecimentos firmados em ações educativas com enfoque na formação cidadã. Tal integração se deu ao longo do segundo semestre de 2019 via Cursos de Letramento Digital ofertados para 18 comunidades situadas no Litoral Centro-Norte do Espírito Santo e vinculadas ao Programa de Educação Ambiental Redes de Cidadania. Este objetiva a mobilização e organização dos pescadores, incentivando o desenvolvimento de maior autonomia e proporcionando um modo de pensar crítico e reflexivo, fortalecendo-os na defesa de seus territórios, na consolidação de seus modos de vida e no seu reconhecimento frente à sociedade. Sob a perspectiva da Educação Ambiental Crítica desenvolveram-se metodologias quantitativas e qualitativas, utilizando-se de variadas técnicas tanto para a coleta de dados quanto para sua consequente análise. Os resultados alcançados confirmam a construção da aprendizagem e do conhecimento por meio de cursos de capacitação que favoreceram a interação e o diálogo. Estes ainda indicam que o protagonismo dos sujeitos da ação foi atingido, o que se vê pela compreensão adquirida de que, dominando novas ferramentas, como as digitais, podem interferir positivamente em suas vidas particulares e em comunidade.
\end{abstract}

Palavras-chave: Educação Ambiental. Formação Cidadã. Processos Educativos.

\begin{abstract}
This paper aims to analyze how citizenship education environments and knowledge affect integration and the way of life of artisanal marine fishery communities. The educational process involved 18 communities located in the Centre-North Coast of Espirito Santo State, members of Environmental Education Program Redes de Cidadania throughout the second half of 2019 at Digital Literacy Class. The Program aims to provide means for mobilization and organization of fishery communities in collective action, encouraging the development of autonomy and providing a critical and reflective thinking. Besides, it aims alto do help strengthening them to defend their territories, sustain their ways of life in a social recognition process. From the perspective of Critical Environmental Education, quantitative and qualitative methodologies were developed, using mixed methods for data collection and analysis. The results achieved confirm the construction of learning and knowledge through training classes that favored interaction and dialogue. These results still indicate that subjects of the action protagonism was achieved, which is seen in their understanding that mastering new tools such as digital ones can positively interfere in their private and communal lives.
\end{abstract}

Keywords: Environmental Education. Citizenship Education. Educational Processes.

\section{Introdução}

Em meio às necessidades dialógicas entre o que é tradicional e o que é contemporâneo, a Educação Ambiental torna-se um importante mecanismo de valorização dos saberes e fazeres de uma comunidade, ampliando as possibilidades de fortalecimento da autonomia e do empoderamento. Por meio da Educação Ambiental Crítica, o diálogo é favorecido, valorizando o contexto histórico das Comunidades Tradicionais Pesqueiras frente a um processo excludente nas relações sociais, políticas e econômicas, além do afetamento por intervenções de ordem territorial, promovidas pela implantação de empreendimentos econômicos industriais, desastres ambientais, expansão urbana e políticas municipais.

Diante de um cenário que os vulnerabiliza na manutenção de seus modos de vida, além de se encontrarem em meio a um contexto de mitigação de impactos ambientais decorrentes do pós-licenciamento de empreendimentos de exploração petrolífera offshore, essas mudanças devem facilitar a ascensão de novos paradigmas apoiados por um pluralismo cultural e por uma política integracionista. Nesta perspectiva, inseremse importantes elementos para uma análise crítica e reflexiva da construção do conhecimento em face das necessidades

1Este trabalho foi financiado pelo PEA-Redes de Cidadania, que integra o Programa de Educação Ambiental regulado pela Nota Técnica CGPEG/ DILIC/IBAMA 01 de 2010, sendo caracterizado como medida de mitigação exigida pelo processo de licenciamento ambiental federal, conduzido pelo Ibama e formalizado por meio do convênio 5400.0107359.18.04 firmado entre a Universidade Vila Velha UVV-ES e a Petrobras. 
das comunidades e de seus moradores perante os processos educacionais e os variados espaços de aprendizagem.

Deve-se também considerar que os processos educacionais aplicados em Comunidades Tradicionais podem e devem adotar uma abordagem de formação direta e indireta dos atores envolvidos, com ênfase na inclusão social e participação cidadã. Para tanto, as estratégias de ensino devem atender as demandas comunitárias por meio da ação participativa e integrativa. Além disso, há que se mediar os conhecimentos tradicionais e tácitos, como forma de valorizar as contribuições do modo de vida local em relação aos processos modernos da educação formal, ainda que crítica. Desta forma, busca-se permitir que esses sujeitos desenvolvam habilidades pautadas pela afirmação de seu saber, garantindo-lhes maior exercício de suas autonomias político-sociais.

Nesse contexto, as ações apresentadas a seguir estão baseadas em uma abordagem colaborativa por meio da mobilização de lideranças comunitárias formais e informais, representantes dos jovens e das mulheres, com vistas ao desenvolvimento de um processo crítico de Educação Ambiental via Letramento Digital. Com a participação ativa dos membros das comunidades, pretende-se possibilitar um espaço de empoderamento coletivo e de mudança, em que o conhecimento acadêmico represente um meio para que a comunidade amplie sua formação cidadã, produza e divulgue conhecimento sobre suas atividades e alcance seus objetivos.

\section{Material e Métodos}

A pesquisa é de natureza quantitativa e qualitativa, onde segundo Lüdke e André (2013, p.35), "os focos de observação são determinados basicamente pelos propósitos específicos de estudo, que por sua vez derivam de um quadro teórico geral, traçado pelo pesquisador". A metodologia consiste em observar para além da realidade, de maneira crítica e reflexiva, tendo em vista o contexto do participante da pesquisa. Para este propósito, nos pautaremos na Aprendizagem Baseada por Problemas-ABP (BARBEL, 1998), sendo uma metodologia de ensino e aprendizagem a partir de problematizações que podem surgir de questionamentos ou de situações-problema tendo em vista casos práticos.

A pesquisa também seguiu o campo exploratório descritivo, utilizando como técnicas de coleta de dados a observação participante, via registros fotográficos e videográficos, questionários, entrevistas, rodas de conversa e relatos de campo. Nesta modalidade, "[...] o pesquisador entra em contato com a comunidade, grupo ou realidade estudada" (MARCONI; LAKATOS, 2011, p.278),

Fundamentando os resultados coletados, a pesquisa teve por finalidade a aplicação prática, que de acordo com Appolinário (2004) tem o objetivo de resolver problemas ou necessidades concretas e imediatas. Fiel a essa compreensão, somando-se ao pensamento compartilhado com Freire (2000, p.67), para o qual “[...] se a educação sozinha, não transforma a sociedade, sem ela tampouco a sociedade muda", a pesquisa analisará a Educação Ambiental em Espaços Educativos Não Formais como recurso facilitador da autonomia social e do empoderamento das Comunidades Tradicionais Pesqueiras do Litoral Centro-Norte do Estado do Espírito Santo.

A definição do recorte espacial dessa pesquisa contempla os Municípios selecionados no âmbito do projeto Redes de Cidadania, com o propósito de atuar na Linha de Ação $\mathrm{A}^{2}$ do Programa de Educação Ambiental-PEA promovido pelo Ibama a partir da Nota Técnica CGPEG/DILIC/IBAMA No. 01/2010. Estas comunidades se situam na área de influência dos empreendimentos petrolíferos offshore, cujo impacto já tem compensação prevista com a adoção de projetos de Geração de Trabalho e Renda-GTR escolhidos pelos impactados. O PEA-Redes de Cidadania atua em 18 comunidades divididas em sete Município, de acordo com o Quadro 1.

Quadro 1 - Recorte espacial do programa de educação ambiental Redes de Cidadania

\begin{tabular}{|c|l|}
\hline Município & \multicolumn{1}{|c|}{ Comunidade(s) } \\
\hline Vitória & Praia do Suá \\
\hline Vila Velha & Itapuã e Prainha \\
\hline Serra & $\begin{array}{l}\text { Bicanga; Carapebus; Jacaraípe; Manguinhos } \\
\text { e; Nova Almeida }\end{array}$ \\
\hline $\begin{array}{c}\text { Aracruz } \\
\text { Linhares }\end{array}$ & $\begin{array}{l}\text { Barra do Riacho; Barra do Sahy e; Santa } \\
\text { Crurra Seca; Degredo; Pontal do Ipiranga; } \\
\text { Povoação e; Regência }\end{array}$ \\
\hline São Mateus & Guriri \\
\hline $\begin{array}{c}\text { Conceição da } \\
\text { Barra }\end{array}$ & Sede \\
\hline Fonte: PEA-Redes de Cidadania
\end{tabular}

Fonte: PEA-Redes de Cidadania

Foram selecionados como atores para esta pesquisa os pescadores artesanais, marisqueiras, bem como seus familiares. Diante disso, foram envolvidos, estrategicamente, filhos, maridos e esposas inscritos nos três Módulos do Curso de Letramento Digital das Redes de Formação do PEA-Redes de Cidadania. Cada um desses atores possui características diferentes que se relacionam ao seu papel dentro do grupo familiar e da comunidade, bem como à familiaridade com as ferramentas a serem utilizadas nas ações educativas.

O PEA-Redes de Cidadania é resultado de um convênio entre a Universidade Vila Velha-UVV/ES e a Petrobras, com o objetivo de capacitar pescadores artesanais e marisqueiras do Litoral Centro-Norte do Espírito Santo, assim como seus familiares para o exercício da cidadania em processos de Licenciamento Ambiental e na Geração de Trabalho e Renda. Sua realização é uma medida de mitigação exigida em processo de Licenciamento Ambiental Federal, conduzido pelo Ibama.

Este projeto objetiva a mobilização e organização dos

2 Organização comunitária para a participação na gestão ambiental, no âmbito do licenciamento ambiental: desenvolver processos formativos junto ao público prioritário definido pelas diretrizes pedagógicas do IBAMA, a ser identificado na região por meio de diagnósticos participativos. 
sujeitos da ação educativa a ser realizada, ou seja, a comunidade pesqueira direta ou indiretamente envolvida na cadeia de produção, de forma a se fortalecerem as ações vinculadas aos eixos de Economia Solidária e Geração de Trabalho e Renda, Meio Ambiente e Licenciamento Ambiental e Letramento Digital. Sua equipe é multidisciplinar, envolvendo profissionais de áreas como educação, relacionamento com comunidades, geografia, urbanismo, antropologia e comunicação social, entre outras. O PEA-Redes de Cidadania também é o ambiente de pesquisa de alunos bolsistas de mestrado da UVV/ES, que desenvolvem seus trabalhos a partir dos desafios identificados no contexto das comunidades contempladas.

Para atender aos eixos temáticos, o PEA-Redes de Cidadania está organizado em três grandes dimensões de atuação: Redes de Conhecimento, Redes de Formação e Redes de Ação, sendo esta não abordada nesse artigo. Cada uma delas está dividida em ciclos destinados a organizar as atividades que são desenvolvidas em cada comunidade, de acordo com o eixo temático, o nível educacional dos sujeitos da ação, a abrangência espacial e a etapa de implantação.

Sendo assim, o atributo crítico, que é conferido ao projeto como sinalizador do seu compromisso com o movimento que articula o ato de conhecer com o ato do transformar necessário, pressupõe o estabelecimento de condições em que não haja dependência de outros para conhecer e agir. Logo,

[...] toda ação educativa deve ser direcionada para a construção da igualdade e promoção das diversidades para que possamos satisfazer nossas necessidades sem opressão, discriminação e reprodução da dominação e dos mecanismos de expropriação. (LOUREIRO, 2015, p.167).

Considera-se que os saberes e fazeres tradicionais por meio dos indivíduos e da coletividade se tornam fundamentais para o ato da emancipação pessoal e comunitária, bem como, na construção da identidade coletiva e conscientização crítica em relação ao mundo. Para tanto, os diálogos firmados partem do (re)pensar as "educações ambientais" praticadas pelas Comunidades Tradicionais de Pescadores Artesanais em seu contexto cotidiano. Torna-se, assim, necessário compreendermos as formas mais apropriadas de transmissão, mediação e potencialização do sentimento de valorização da cultura, autonomia social e defesa da territorialidade de cada comunidade, garantindo a educação pela significação dos conteúdos curriculares.

De acordo com as Diretrizes Curriculares Nacionais para a Educação Ambiental (BRASIL, 2012, p.2), entendese que esta venha a ser: "[...] uma dimensão da educação", sendo "[...] atividade intencional da prática social, que deve imprimir ao desenvolvimento individual um caráter social em sua relação com a natureza e com os outros seres humanos". Tal posicionamento educacional é corroborado pelo Inciso $\mathrm{V}$ do Artigo $3^{\circ}$ referente ao Decreto $n^{\circ} 6040$ de 7 de fevereiro de 2007 da Política Nacional de Desenvolvimento Sustentável dos Povos e Comunidades Tradicionais, onde destaca que devemos:
Garantir e valorizar as formas tradicionais de educação e fortalecer processos dialógicos como contribuição ao desenvolvimento próprio de cada povo e comunidade, garantindo a participação e controle social tanto nos processos de formação educativos formais quanto nos não-formais (BRASIL, 2007, s/p).

Essa perspectiva evidencia a atuação do processo de globalização, em sua tendência de homogeneizar o conhecimento e os saberes e fazeres que são parte de pequenos grupos e comunidades específicas. Nesse sentindo, a Educação Ambiental representa um importante papel na transmissão e conservação do que é tradicional, tornando-se um espaço de voz para as comunidades e permitindo a exposição de seus anseios e necessidades: "[...] visando à superação de mecanismos de controle e de dominação" (REIGOTA, 2012, p.13).

A Educação Ambiental Crítica, por sua vez, deve ser traduzida para a atualidade dos sujeitos da ação educativa envolvidos, como potencializadora da interação entre sujeitos, sendo oposta aos sistemas de instrução baseadas no ensino como mera transferência de conteúdo, valorizando a realidade concreta de cada comunidade, nos sujeitos com seus saberes, fazeres, perspectivas e modos de resistência e (re)existência. Pode-se dizer que tal pesquisa se faz: "[...] em movimento, no acompanhamento de processos que nos tocam, nos transformam e produzem mundos" (BARROS; KASTRUP, 2010). Diante disso, compreender as particularidades de cada comunidade tradicional faz-se pertinente, permitindo que seja proposta uma relação entre o ambiente e a sociedade a partir da perspectiva local, enfocando a cultura como processo de conformação de relações sociais e as atividades tradicionais comunitárias, bem como, as escalas político-econômicas.

Considerando que a aprendizagem pode ocorrer em qualquer momento e local, os espaços educativos devem estar conectados e fazer parte do cotidiano das pessoas. Tais espaços designam “[...] um processo com várias dimensões que possibilita [...] uma leitura do mundo do ponto de vista de compreensão do que passa ao seu redor", sendo locais concretos de "[...] formação com a aprendizagem de saberes para a vida em coletivos" (GOHN, 2009, p.31-32). A partir deste contexto, reforça-se o pensamento de Vygotsky (2007) quando diz que a relação do homem com o mundo não é direta, mas mediada por meio de instrumentos e signos que ocorre por meio da experiência pessoal ou compartilhada. Este pensador ainda fundamenta que as funções psicológicas, como linguagem e memória, são construídas ao longo da história social do homem e sua relação com o mundo, considerandose que a educação é a apropriação da cultura e por meio da educação nos fazemos sujeitos humanos e históricos.

\section{Resultados e Discussão}

\subsection{Organização e Planejamento do Programa de Educação Ambiental}

Ao se propor um programa educacional aos envolvidos, 
tornou-se necessário considerar dois fatores: as dificuldades cotidianas que enfrentam diante das particularidades de sua cultura, e; entender o modo de vida, seja na organização de trabalho, seja nas questões familiares. Consequentemente, compreender algumas necessidades individuais e coletivas e o sentimento de pertencimento dos atores ao ambiente pesquisado foi determinante para elaborarmos ações educacionais pautadas em práticas colaborativas e atividades em que o aluno fosse protagonista da sua aprendizagem.

Logo, o PEA-Redes de Cidadania, em virtude de sua curta duração prevista, de 36 meses, e tendo por base os objetivos que almeja alcançar, foi formulado para atuar em três dimensões ${ }^{3}$, sendo uma delas as Redes de Formação. Esta é responsável pela oferta de cursos de formação em Letramento Digital, Economia Solidária e Geração de Trabalho e Renda, além de Meio Ambiental e Licenciamento Ambiental. De acordo com a Nota Técnica CGPEG/DILIC/IBAMA No. 01/10 o PEA deve articular a "promoção de processos educativos voltados ao desenvolvimento da gestão ambiental compartilhada" (IBAMA, 2010, p.3).

O primeiro curso ofertado foi justamente o de Letramento Digital, com o intuito de auxiliar os alunos no uso dos recursos computacionais básicos e no acesso consciente à internet. Neste sentido, o curso não se constitui apenas no treinamento de pessoas para o campo da informática, mas sim no investimento das suas competências, de modo a capacitá-las nas tomadas de decisões e na utilização adequada das ferramentas digitais que possam auxiliar nas questões relacionadas ao Meio Ambiente e Licenciamento Ambiental, bem como na promoção da Economia Solidária e Geração de Trabalho e Renda para as Comunidades Pesqueiras Artesanais. Diante deste contexto, o curso foi definido para uma carga horária total de 56 horas, divididas em três Módulos, a saber: Ciclo básico - Informática básica; Ciclo intermediário - Pacote Office e Internet, e; Ciclo Avançado - Recursos Audiovisuais e Redes Sociais.

Para efetivação do curso de Letramento digital foram realizadas três etapas fundamentais. $\mathrm{Na}$ primeira foram realizadas reuniões com as comunidades, apresentando o conteúdo programático, a dinâmica das aulas e a importância do Letramento Digital no contexto da Educação Ambiental. Estas reuniões foram importantes para decidir junto às comunidades os melhores dias e horários para que as aulas acontecessem.

Na segunda etapa ocorreram as inscrições para o curso, nas quais foram disponibilizadas 20 vagas para cada comunidade. Se considerando que são 18 comunidades atendidas pelo PEA-Redes de Cidadania, tivemos um total de 360 vagas ofertadas. Caso o número de candidatos fosse maior do que o de vagas disponíveis por comunidade, o mecanismo de seleção seria o sorteio ${ }^{4}$. Neste caso, verificou-se a necessidade de sorteio apenas em quatro comunidades - Itapuã, em Vila Velha; Sede, em Conceição da Barra; Barra Seca e Degredo, ambas em Linhares -, sendo importante saber que o único prérequisito para o curso era fazer parte do público contemplado pelo PEA. Assim, para ter esse controle, foi utilizado o registro ou protocolo de pesca para identificar quem realmente poderia participar do curso e o grau de parentesco entre os interessados. Por fim, a terceira etapa se direcionou a organização dos espaços das aulas, privilegiando-se locais próximos às comunidades, a logística, tendo em vista a necessidade de se transportarem muitos alunos interioranos e idosos, com dificuldades de mobilidade, para os locais de realização do curso, a alimentação, com o fornecimento de lanches para o período de quatro horas previsto para cada dia de aula, e a elaboração do material didático em si.

Ressaltamos que o material didático foi elaborado exclusivamente para o Curso de Letramento Digital, sendo três apostilas, uma para cada Módulo. Estas apostilas priorizaram aspectos como uma leitura simples, clara e objetiva, trazendo ilustrações atrativas e que remetessem a realidade do público atendido pelo PEA-Redes de Cidadania.

Por esses e outros motivos, durante a fase de planejamento das aulas, o material didático foi elaborado com o intuito de potencializar a interação entre sujeitos a partir de seus modos de vida, sendo priorizadas abordagens e práticas opostas aos sistemas de instrução baseados no ensino como mera transferência de conteúdo. Portanto, tornou-se importante na elaboração das apostilas valorizar as relações pessoais e sua relevância por meio da práxis cotidiana, dos saberes de fora da sala de aula em meio as teorias aplicadas no ambiente de formação, provocando a reflexão e crítica dos sujeitos envolvidos no processo de ensino e aprendizagem. Neste sentido, teoria e prática são postas como faces indissociáveis que permitem correlacionar os conhecimentos científicos com o cotidiano dos alunos.

Os professores do Curso de Letramento Digital, aqui denominados de Agentes de Formação, foram selecionados com base em suas aptidões curriculares, bem como com base em suas proximidades, sejam geográficas, sejam socioculturais das Comunidades de Pescadores Artesanais, tendo em vista se julgar que tais características facilitariam a identificação e comunicação com os sujeitos da ação educativa a partir da troca de experiências comuns. Ademais, estes foram treinados em encontros prévios para que conhecessem o PEA-Redes de Cidadania, seus princípios e objetivos, as características genéricas e específicas dos potenciais alunos a ingressarem no

3 Paralelamente, e integrada às ações realizadas pelas Redes de Formação, acontecem às atividades das outras 02 (duas) dimensões do PEA-Redes de Cidadania, sendo elas as: Redes de Conhecimento - que preveem atividades de pesquisa objetivando não apenas conhecer as comunidades, mas também estimular que elas produzam conhecimento sobre si mesmas; Redes de Ação - compreendendo ciclos de atividades práticas de caráter amplo, destinados a complementar o aprendizado das Redes de Formação.

4 Importante ressaltar que esse mecanismo "sorteio" não é o mais adequado, entretanto, fez-se necessário devido ao número de equipamentos disponíveis, bem como a limitação dos recursos financeiros. 
curso, assim como para que fossem formados na utilização do material didático a ser aplicado nas aulas.

Sendo assim, estes foram orientados para que, ao longo das aulas fossem propostas atividades práticas balizadas pelo trabalho colaborativo, valorizando aspectos culturais locais e os conhecimentos prévios dos alunos. Para tanto, o planejamento das atividades em equipe foi direcionado para que todos os alunos tenham responsabilidade nos resultados alcançados, destacando-se alguns propósitos, a saber: o esforço deve ser para se alcançar um fim comum; deve-se primar, sempre, pela maior integração e qualidade dos relacionamentos; a habilidade de cada membro é algo que soma as habilidades dos demais. Com isso, esperasse ser possível melhorar o desempenho individual e coletivo das turmas. Dentro destas propostas o aluno se tornou sujeito ativo no processo de construção do saber, sendo que para cada dinâmica deveriam ser observadas e respeitadas as características de cada turma.

\subsection{Resultados alcançados}

No Quadro 2 apresentamos os dados aglutinados referentes às atividades das Redes de Formação em seu primeiro curso ofertado, o de Letramento Digital.

Quadro 02 - Curso de Letramento Digital

\begin{tabular}{|c|c|c|}
\hline Ações & Resultados & Observações \\
\hline $\begin{array}{c}\text { Reuniões } \\
\text { realizadas }\end{array}$ & 34 & $\begin{array}{c}\text { Em todas as comunidades } \\
\text { atendidas pelo PEA }\end{array}$ \\
\hline $\begin{array}{c}\text { Pessoas } \\
\text { atendidas }\end{array}$ & 460 & $\begin{array}{c}\text { Durante as reuniões de } \\
\text { apresentação do PEA/curso }\end{array}$ \\
\hline $\begin{array}{c}\text { Vagas } \\
\text { disponibilizadas }\end{array}$ & 360 & $\begin{array}{c}\text { 20 vagas disponibilizadas por } \\
\text { comunidade }\end{array}$ \\
\hline $\begin{array}{c}\text { Inscrições } \\
\text { realizadas }\end{array}$ & 273 & $\begin{array}{c}\text { Considerando primeira e } \\
\text { segunda rodada de inscrições }\end{array}$ \\
\hline Média de idade & 37 & $\begin{array}{c}\text { Considerando todos os alunos } \\
\text { matriculados }\end{array}$ \\
\hline $\begin{array}{c}\text { Quantidade de } \\
\text { alunos formados }\end{array}$ & 212 & $\begin{array}{c}\text { Considerando os concluintes } \\
\text { dos 03 (três) Módulos do } \\
\text { curso ofertado }\end{array}$ \\
\hline \multicolumn{2}{|c|}{ Fonte: Dados da pesquisa. }
\end{tabular}

Considerando-se o Quadro 2, tivemos 273 inscrições realizadas em 17 comunidades participantes, contemplando $78 \%$ das vagas ofertadas. Uma das comunidades contempladas pelo PEA-Redes de Cidadania, a da Prainha, localizada no Município de Vila Velha, não aderiu ao curso. As turmas foram formadas por lideranças formais e informais das comunidades, pessoas buscando outras fontes de renda, novos conhecimentos, jovens, idosos, homens e mulheres, com pouco ou nenhum grau de escolaridade. Tais características formaram turmas plurais em seu sentido mais amplo.

$\mathrm{O}$ índice de desistência e/ou evasão, levando-se em consideração o número de ingressantes e o número de alunos concluintes (i.e. formados), ficou em torno de $20 \%$, sendo considerado baixo em relação às características apresentadas pelos alunos, como o reduzido grau de escolaridade e/ou tempo afastado dos espaços de aprendizagem, sejam formais ou não formais. Por meio de questionário aplicado, constatamos que
$52 \%$ dos alunos concluíram apenas o Ensino Fundamental, sendo que $73 \%$ não estudavam no período do curso. Os pescadores artesanais, marisqueiras e familiares contemplados pela formação alegaram não ter estímulo para continuar os estudos, especialmente devido aos conteúdos aplicados na Educação Formal não dialogarem com a realidade pesqueira das comunidades.

Outros indicadores, que merecem destaque, apurados neste mesmo questionário supramencionado, dizem respeito à realidade econômica e aos anseios dos alunos. Dos ingressantes no Curso de Letramento Digital, 51\% declararam possuir renda familiar de até 01 (um) salário mínimo, sendo que $84 \%$ do total declarou renda pessoal de até 01 (um) salário mínimo, o que leva a crer que um contingente significativo destes podem ser classificados como arrimos de família. Ademais, 60\% dos alunos exercem atividades ligadas direta ou indiretamente à pesca artesanal. Quanto aos anseios dos membros das comunidades que se inscreveram e concluíram o Curso de Letramento Digital, estes podem ser sintetizados nos indicadores levantados (Quadro 3):

Quadro 03 - Indicadores observados quando aos anseios dos concluintes do Curso de Letramento Digital

\begin{tabular}{|l|c|}
\hline \multicolumn{1}{|c|}{ Indicadores } & $\%$ \\
\hline $\begin{array}{l}\text { Acredita que o Curso de Letramento Digital é importante } \\
\text { para a Comunidade Pesqueira }\end{array}$ & 82 \\
\hline $\begin{array}{l}\text { Acredita que o Curso de Letramento Digital irá ajudar } \\
\text { no crescimento profissional }\end{array}$ & 63 \\
\hline $\begin{array}{l}\text { Escolheu o curso buscando potencializar sua formação/ } \\
\text { participação cidadã }\end{array}$ & 65 \\
\hline $\begin{array}{l}\text { Acredita que o Curso de Letramento Digital contribui } \\
\text { para a prática cotidiana }\end{array}$ & 82 \\
\hline $\begin{array}{l}\text { Avaliou como "excelente" ou "muito bom” o } \\
\text { conhecimento do Agente de Formação e os conteúdos } \\
\text { teórico-práticos presentes nas Apostilas e aplicados } \\
\text { durante as aulas }\end{array}$ & 79 \\
\hline Considerou "excelente" a organização das aulas. & 87 \\
\hline
\end{tabular}
Fonte: Dados da pesquisa.

Tais dados enfatizam uma dupla constatação. A primeira diz respeito a necessidade de se aproximar e ouvir os atores prioritários da pesquisa, tanto para a aquisição de novos conhecimentos sobre estes e seus modos de vida quanto para se buscar ofertar atividades e cursos direcionados ao atendimento das demandas locais e/ou que se mostram prementes para os sujeitos da ação educativa, neste caso os Pescadores Artesanais Marítimos atendidos pelo PEA-Redes de Cidadania. Estas iniciativas, por si só, potencializam as possibilidades de sucesso das atividades junto a tais grupos, seja para os promotores da ação, seja para os sujeitos da ação ao terem seus anseios atendidos.

No presente relato, observa-se uma grande preocupação de pescadores artesanais, marisqueiras e familiares quanto as suas capacitações para a Geração de Trabalho e Renda, buscando melhores oportunidades pessoais e profissionais. Isto se agrava pela realidade que estes vem vivenciando nos últimos 05 (cinco) anos, ao serem impactados, direta e/ou 
indiretamente, pelo rompimento da barragem de rejeitos de Fundão em Mariana-MG, pertencente a Samarco, no final do ano de 2015, impedindo a prática da atividade pesqueira em muitas regiões. ${ }^{5}$

A segunda constatação, observada por meio dos indicadores coletados junto aos alunos concluintes do Curso de Letramento Digital, se refere aos anseios dos sujeitos da ação educativa quanto a sua participação no curso, bem como o grau de satisfação alcançado junto a estes ao se formarem. Os destaques ficam por conta da maioria dos alunos (82\%) acreditarem na importância do Letramento Digital para suas comunidades, sendo que número similar julga que o curso e sua temática contribuam para as práticas cotidianas, sejam individuais e/ou comunitárias. Soma-se a isso o fato de que acima de $60 \%$ dos alunos consideraram a formação pertinente para o crescimento profissional e, principalmente, para potencializar suas formações/participações cidadãs. Um sinal positivo de que os alunos compreenderam e coadunaram com os objetivos do PEA-Redes de Cidadania.

Por outro lado, fora a coerência observada nos dados coletados com aquilo que se esperava em termos de perfil dos alunos e atendimento às suas demandas particulares e/ ou comunitárias, enfatiza-se também o nível de satisfação atingido com pescadores, marisqueiras e familiares formados em Letramento Digital. Neste sentido, notam-se indicadores próximos ou superiores a $80 \%$ de satisfação tanto referente aos conteúdos programáticos, material didático e Agentes de Formação quanto referente a organização das aulas no que diz respeito a logística, local de realização dos encontros, fornecimento de lanches, dentre outros. Tais dados, mais uma vez, referendam o sucesso das práticas educativas adotadas com as Comunidades de Pescadores Artesanais.

Assim sendo, a partir dos dados, relatos orais coletados e vivências observadas junto aos alunos ${ }^{6}$, o PEA-Redes de Cidadania conseguiu atingir grande parte dos resultados esperados na oferta de seu primeiro curso de formação, que balizará futuras ações e futuros cursos nestas comunidades. Apesar disso, cabe registrar que muitos dos resultados esperados dizem respeito a mudanças comportamentais e a aplicação dos recursos apreendidos em seus cotidianos, na vida comunitária, resultados estes que, muitas vezes, são subjetivos, difíceis de serem mensurados em um curto espaço de tempo e sem um acompanhamento próximo dos sujeitos da ação educativa nos próximos anos, algo que se almeja realizar.

\section{Conclusão}

O PEA-Redes de Cidadania tem, entre seus propósitos, se tornar agente de mudanças, impulsionando transformações e formando indivíduos criativos, empreendedores e dotados de consciência global. Diante disso, as aulas ofertadas foram adequadas do ponto de vista tecnológico e metodológico, valorizando cada saber e fazer, dialogando e se aproximando ao cotidiano de cada comunidade atendida.

O acompanhamento das atividades não se restringiu a aplicação do Curso de Letramento Digital, prosseguindo durante as demais etapas do projeto, corroborando o reconhecimento que é dado ao contexto da intervenção, bem como se atendeu ao princípio de se verificar a viabilidade destes cursos quanto a exequibilidade das propostas num processo retroalimentar das ações. Neste contexto, pretendese que o exercício da cidadania perante os empreendimentos públicos e privados se dê de forma mais efetiva, algo que só pode ser observado com um acompanhamento do porvir nessas comunidades.

Por outro lado, o enfrentamento do desafio pedagógico de viabilizar à atores que, em sua maioria, se encontravam afastados de processos educacionais, levando-os a compreensão para além de suas evidências superficiais do cotidiano, reforça a necessidade de se pensarem e assumirem princípios como os da Educação Ambiental Crítica. Tais princípios, em especial, são os responsáveis por gestar a transformação tanto no comportamento quanto na consciência destas comunidades em relação aos seus valores e atitudes, fazendo crer que estes se perpetuarão em meio a seus modos de vida como conquistas necessárias a novas ações, sustentáveis, de atores sociais individuais e coletivos sobre o ambiente.

Assim sendo, reforça-se o fato de que tais princípios devem e foram trabalhados com os sujeitos da ação educativa não apenas como receptores de informações, mas como indivíduos que pensam, agem e remodelam as informações de acordo com suas práticas, experiências e culturas e, portanto, a partir dos distintos significados encontrados. Logo, a Educação Ambiental Crítica contribui na derrubada de certezas ao permitir raciocínios amplos, se permitindo apreender e ensinar via histórias de vida, tradições, saberes e fazeres e não como uma concepção tendenciosamente colonizadora.

Nessa perspectiva, pensar o empoderamento e o incentivo a participação cidadã de Comunidades Tradicionais significa pensar em habilitá-los com meios e recursos para o exercício de seu saber. Para tanto, a dinâmica trazida pelas estratégias do primeiro curso ofertado pelo PEA-Redes de Cidadania, o de Letramento Digital, permite, bem como permitiu no caso aqui retratado, que esses sujeitos da ação educativa se apropriassem de espaços que ultrapassam os limites comunitários, dando margem para que percebam o alcance e se apliquem em uma participação e atuação política que se mostre mais eficiente

5 O rompimento lançou 55 milhões de metros cúbicos de lama com rejeitos de ferro e outros minerais no subdistrito Bento Rodrigues, em Mariana. Estes rejeitos, por sua vez, afetaram os rios Gualaxo do Norte e do Carmo, afluentes do Rio Doce, bem como a própria bacia hidrográfica deste, até desaguar no Oceano Atlântico, na altura do Distrito de Regência Augusta, no Município de Linhares-ES, de onde espalhou-se por todo o mar territorial do litoral centro-norte do Espírito Santo (SERRA, 2018).

6 Alguns destes relatos podem ser visualizados no Canal do YouTube do PEA-Redes de Cidadania: $<$ https://www.youtube.com/channel/UC79o4Ev5T_ jj2LZ72_fpEAw>. 
frente às suas demandas e interesses.

Ao mesmo tempo, a experiência deste projeto evidencia a necessidade de que todos os que estejam envolvidos na educação pensem, analisem e planejem ações pedagógicas inovadoras, motivando e potencializando o ensino por meio de processos significativos. Para tanto, novos processos devem ser considerados enquanto vias de construção e de transformação através de novas estratégias, intervenções e tarefas que possibilitem o desenvolvimento de habilidades e de competências, tais como: aprender a aprender, criar e empreender, gerenciar informações, derivar dos resultados de pesquisa novas possibilidades de aplicações no âmbito da atuação profissional, modificar padrões estabelecidos e identificar diferentes possibilidades de atuação social, dentre outros.

\section{Referências}

APPOLINÁRIO, F. Dicionário de metodologia científica: um guia para a produção do conhecimento científico. São Paulo: Atlas, 2004.

BARROS, L.P.; KASTRUP, V. Cartografar é acompanhar processos. In: PASSOS, E.; KASTRUP, V.; ESCÓSSIA, L. (Org.). Pistas do método da cartografia: pesquisa-intervenção e produção de subjetividades. Porto Alegre: Sulina, 2010.

BARBEL, N.A.N. A problematização e a aprendizagem baseada em problemas: diferentes termos ou diferentes caminhos? Interface Com. Saúde Educ., v.2, n.2, p. 1-16, 1998. doi: https:// doi.org/10.1590/S1414-32831998000100008.

BRASIL. Política Nacional de Desenvolvimento Sustentável dos Povos e Comunidades Tradicionais. 2007. Disponível em: <http://www.planalto.gov.br/ccivil 03/ Ato2007-2010/2007/ Decreto/D6040.htm>. Acesso em: 1 ago. 2020.

BRASIL. Diretrizes Curriculares Nacionais para a Educação Ambiental. 2012. Disponível em: <http://portal.mec.gov.br/ dmdocuments/rcp002_12.pdf>. Acesso em: 1 ago. 2020.

FREIRE, P. Pedagogia da indignação: cartas pedagógicas e outros escritos. São Paulo: UNESP, 2000.

GOHN, M.G. Educação não formal, educador(a) social e Projetos sociais de inclusão social. Rev. Meta Aval., v.1, n.1, p.28-43, 2009. doi: http://dx.doi.org/10.22347/2175-2753v1i1.1.

IBAMA. Nota Técnica Cgpeg/Dilic/Ibama No 01/10 de 10 de fevereiro de 2010: Diretrizes para a elaboração, execução e divulgação dos programas de educação ambiental desenvolvidos regionalmente, nos processos de licenciamento ambiental dos empreendimentos marítimos de exploração e produção de petróleo e gás. Brasília, 2010. Disponível em: <https:// www.comunicabaciadesantos.com.br/sites/default/files/Nota Tecnica_01-10_Programas_de_Educacao_Ambiental.pdf $>$. Acesso em: 17 set. 2020.

LÜDKE, M.; ANDRÉ, M.E.D.A. Pesquisa em educação: abordagens qualitativas. São Paulo: EPU, 2013.

LOUREIRO, C.F.B. Educação ambiental e epistemologia crítica. Rev. Eletr. Mest. Educ. Amb., v.32, n.2, p. 159-176, 2015. doi: https://doi.org/10.14295/remea.v32i2.5536.

MARCONI, M.A.; LAKATOS, E.M.. Metodologia cientifica. São Paulo: Atlas, 2011.

REIGOTA, M.. O que é Educação Ambiental. São Paulo: Brasiliense, 2012.

SERRA, C. Tragédia em Mariana: a história do maior desastre ambiental do Brasil. Rio de Janeiro: Record, 2018.

VYGOTSKY, L.S. A formação social da mente. São Paulo: Martins Fontes, 2007. 